\title{
Measured and simulated thermal behaviour in rammed earth houses in a hot-arid climate. Part A: Structural behaviour
}

\author{
C.T.S. Beckett ${ }^{\mathrm{a}}$, R. Cardell-Oliver ${ }^{\mathrm{b}, *}$, D. Ciancio $^{\mathrm{a}}$, C. Huebner ${ }^{\mathrm{c}}$ \\ ${ }^{a}$ School of Civil, Environmental and Mining Engineering, The University of Western Australia \\ ${ }^{b}$ School of Computer Science $\&$ Software Engineering, The University of Western Australia \\ ${ }^{c}$ Institute for Industrial Data Processing and Communication, University of Applied Sciences \\ Mannheim
}

\begin{abstract}
Heating and cooling of residential buildings consumes around ten percent of the world's energy. One approach for reducing these costs is to exploit the high thermal mass of sustainable building materials, for example rammed earth (RE), for intelligent solar passive design. However, there is a lack of scientific evidence about the thermal performance of RE houses in real-world settings.

This research investigated to what extent thermal performance in unconditioned RE structures in rural Australia can be captured by current accreditation software. Two custom-designed houses were built in the hot-arid city of Kalgoorlie-Boulder, Western Australia: one comprising traditional solid cementstabilised rammed earth walls (RE) and the other walls with an insulating polystyrene core (iRE). Otherwise the houses were identical in orientation and design. The houses were instrumented to monitor indoor temperature and humidity conditions prior to and during occupancy. Results were compared to those simulated using cutting-edge assessment software BERS Pro (v4.3) as an example of that used for energy efficiency accreditation in Australia. This first paper in this series discusses the houses' construction and instrumentation and results obtained during the unoccupied period, i.e. those purely demonstrative of the structure's
\end{abstract}


thermal performance. A second paper in the series presents data gathered during occupancy, to contrast occupant thermal comfort with that predicted numerically.

Measured data showed that both houses performed nominally-identically: the houses did not receive any relative benefit from including iRE. Simulated data was also similar per house. However, measured performance did not match that simulated: simulated rooms had poorer thermal stability and lag and, consequently, exaggerated internal temperature variations. Collected data has been made publicly available for future analyses.

Keywords: rammed earth, insulated rammed earth, thermal stability, thermal lag, environmental monitoring, rural housing

${ }^{*}$ Corresponding author

Email address: rachel.cardell-oliver@uwa.edu.au (R. Cardell-Oliver) Preprint submitted to Elsevier 
1 Contents

2 I 1 Introduction 5

$\begin{array}{llll}3 & 2 & \text { House design } & 6\end{array}$

$\begin{array}{llll}4 & 3 & \text { Instrumentation } & 9\end{array}$

$5 \quad 3.1$ Sensor Types $\ldots \ldots \ldots \ldots \ldots$

$6 \quad 3.2$ Installation . . . . . . . . . . . . . . . . . 13

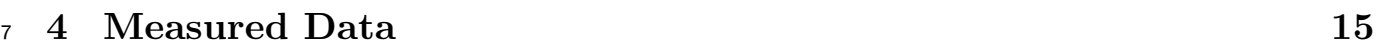

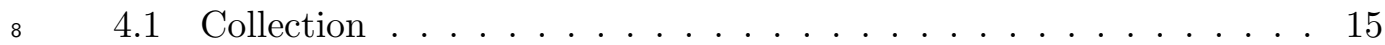

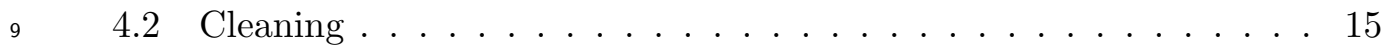

$10 \quad 4.3$ Visualisation and Analysis . . . . . . . . . . . . . 16

$\begin{array}{llll}11 & 5 & \text { Simulated Data } & 16\end{array}$

$\begin{array}{llll}12 & 6 & \text { Thermal Performance Metrics } & 17\end{array}$

$13 \quad 6.1$ Thermal stability . . . . . . . . . . . . . . 18

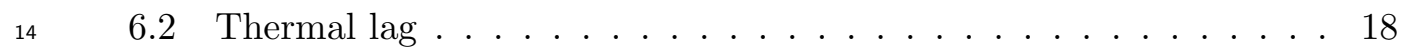

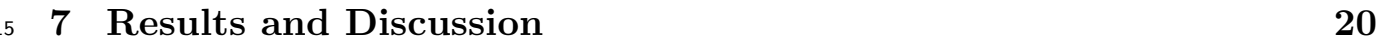

${ }_{16} \quad 7.1$ Thermal stability . . . . . . . . . . . . . . . . . 21

${ }_{17} \quad 7.1 .1$ Measured performance . . . . . . . . . . . 21

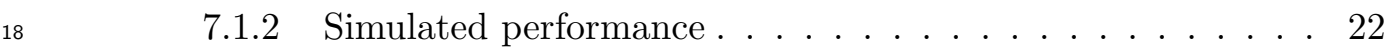

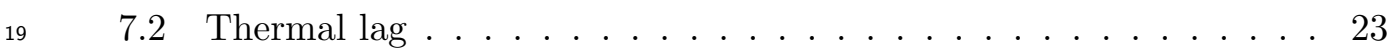

${ }_{20} \quad 7.2 .1 \quad$ Measured performance $\ldots \ldots \ldots \ldots \ldots$

${ }_{21} \quad 7.2 .2 \quad$ Simulated performance $\ldots \ldots \ldots \ldots \ldots \ldots$

$22 \quad 7.3$ Temperature profiles in the walls . . . . . . . . . . 25 


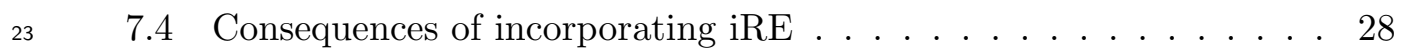

$\begin{array}{lll}24 & 8 & \text { Conclusions }\end{array}$ 
44 not provide adequate performance improvement for its cost depending on the

45 building's design, location and use.

46 This series examines the ability of current energy accreditation software BERS

47 Pro, (v4.3), typical of that used in Australia, to simulate the thermal performance

48 of an unconditioned RE and iRE house built in Kalgoorlie-Boulder, Western Aus-

\section{Introduction}

Almost ten percent of the world's annual energy consumption is used for heating and cooling residential buildings [3, 19]. Reducing this energy demand, even by a small amount, would yield significant environmental and economic savings [23]. Adopting passive thermal designs is one way to achieve this. A key component of this approach is the intelligent use of thermal mass; the passive ability to absorb and retain heat energy [24].

Rammed earth (RE) elements have high thermal mass but low thermal resistance. RE elements consequently perform poorly under current heating and cooling energy efficiency calculations [22]. In response, RE practitioners around the world developed insulated cavity RE walls (iRE), comprising a central insulation panel flanked by external RE leaves. Hall and Allinson [14] and Dong et al. [13] demonstrated that this innovation successfully addressed poor predicted thermal properties whilst retaining the same aesthetic appeal as traditional RE walls. However, iRE construction is slower, and so more costly, owing to the need to compact material either side of the central panel. Furthermore, it is well understood that wall thermal resistance is not the sole predictor of a building's thermal behaviour; rather, the performance of the building as a complete system must be taken into account [20]. Therefore, substituting iRE for RE may or may tralia. Both houses were designed to optimise passive solar behaviour and both 
50

exceeded the minimum energy efficiencies required for construction under the Australian Nationwide House Energy Rating Scheme (NatHERS). This paper, being the first in the series, describes the house construction and instrumentation processes and examines the thermal performance of the structures with no occupants. Measured and simulated performance were contrasted using thermal stability and thermal lag. Measured performance was superior to that predicted by the simulations for both houses, particularly in rooms with lightweight external walls or north-facing floor-to-ceiling windows.

\section{House design}

Kalgoorlie-Boulder in Western Australia was selected because its arid climate (Köppen Classification Bwh) is well suited to passive indoor thermal and humidity regulation using high thermal mass walls [1]. Temperatures in KalgoorlieBoulder can exceed $45^{\circ} \mathrm{C}$ in Summer and drop to freezing in Winter. As such, houses are almost exclusively fitted with large artificial heating and cooling units that consume a considerable portion of their annual energy and water (through evaporative cooling) budgets [6,17]. A key aim of this project was to investigate to what extent adopting passive solar design principles founded on using RE could reduce dependence on artificial climate control.

Two houses were custom-designed comprising several features to promote beneficial passive solar behaviour: both made extensive use of high thermal mass $\mathrm{RE}$ or iRE walls, the living room was placed centrally with a high (3.6m) ceiling and central vent to encourage air flow and a wide veranda shaded the northfacing living room windows. Neither house was equipped with means of artificial heating or cooling, however both houses featured ceiling fans in the living rooms 
74

and bedrooms and a central vent in the living rooms connected to a Venturi fan at the roof's apex.

Figure 1 shows the houses' floor plan and orientation. The rightmost house in Figure 1 comprised 300mm thick monolithic RE walls throughout. The leftmost comprised a mix of 300mm thick iRE and monolithic 300mm RE external walls and $300 \mathrm{~mm}$ monolithic RE internal walls. Both houses featured lightweight timber stud/insulated steel panel ("Colorbond" walling system, insulation Rvalue $=1.5 m^{2} K / W$ ) external walls in the kitchens and bathrooms and both had steel sheet cladding roofs with batt insulation $\left(\mathrm{R}\right.$-value $\left.=3.0 \mathrm{~m}^{2} \mathrm{~K} / \mathrm{W}\right)$ and timber lining. Externally, the houses appeared identical. For convenience, these houses will be referred to hereafter as the "monolithic" and "insulated" houses respectively.

The RE components were stabilised with roughly $9 \%$ by mass of dry soil of Portland cement and compacted to a dry density of approximately $2050 \mathrm{~kg} / \mathrm{m}^{3}$ using a reciprocating pneumatic hammer. Raw soil was obtained from a Coolgardie, roughly 50km from Kalgoorlie-Boulder, from a pit previously used by the contractor, and combined in 3 parts soil to 1 part river sand to improve particle grading. The iRE walls were formed from a central $50 \mathrm{~mm}$ thick extruded polystyrene panel, flanked by two $125 \mathrm{~mm}$ RE leaves.

(Insert Figure 1 somewhere near here)

iRE is used in several countries around the world (e.g. Krayenhoff [16]) but is relatively new to Australia. Therefore, concessions were made to structural integrity for iRE panel design. Panels were built with a 300mm monolithic RE border around their extremities (except at the base) and H-shaped ties, cut from $10 \mathrm{~mm}$ reinforcing bar mesh, were placed at $600 \mathrm{~mm}$ height intervals connecting the leaves. Insulation was not used in any panels $<1000 \mathrm{~mm}$ width, for example 


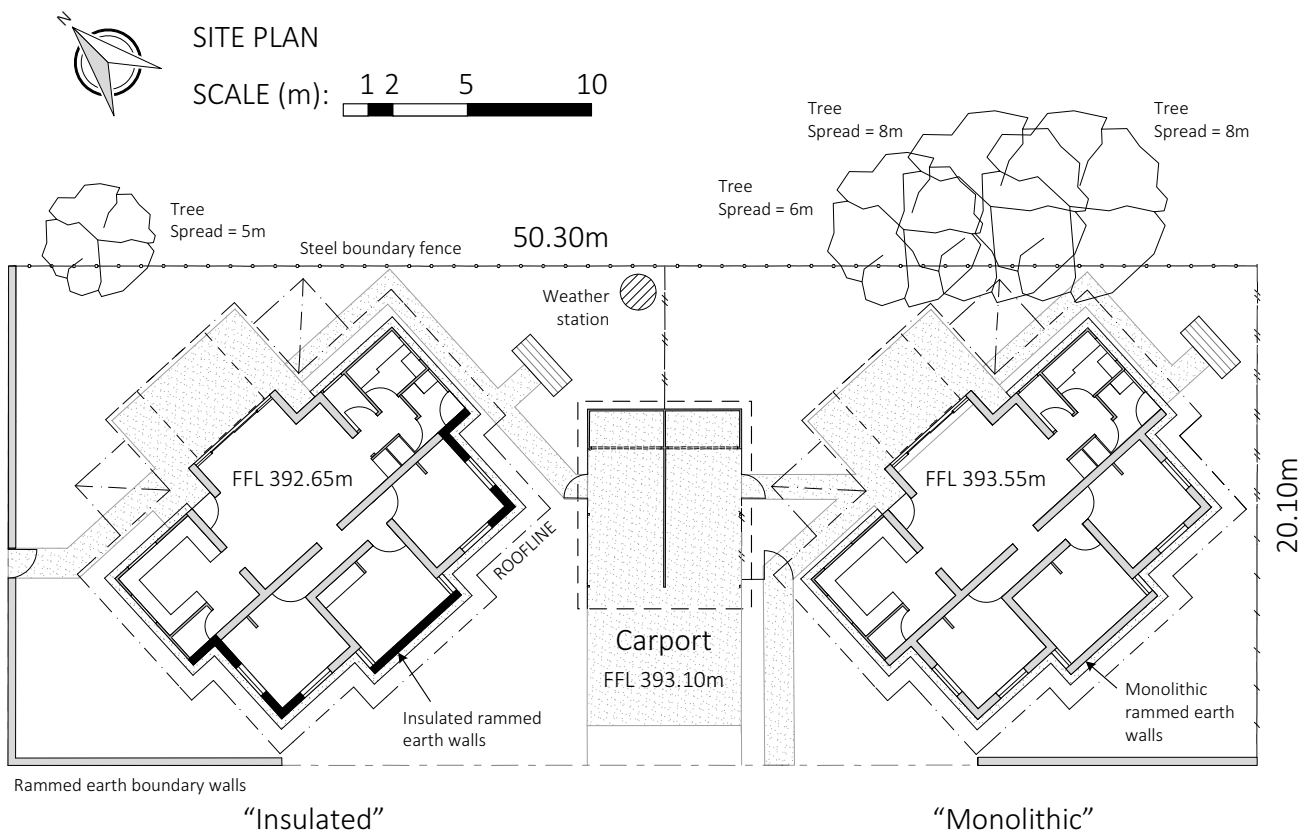

Figure 1: Site plan for the two houses. RE walls are shown in grey and iRE walls in black. Thin grey walls denote lightweight "Colorbond" walling construction. FFL: Finished Floor Level (above mean sea level) 


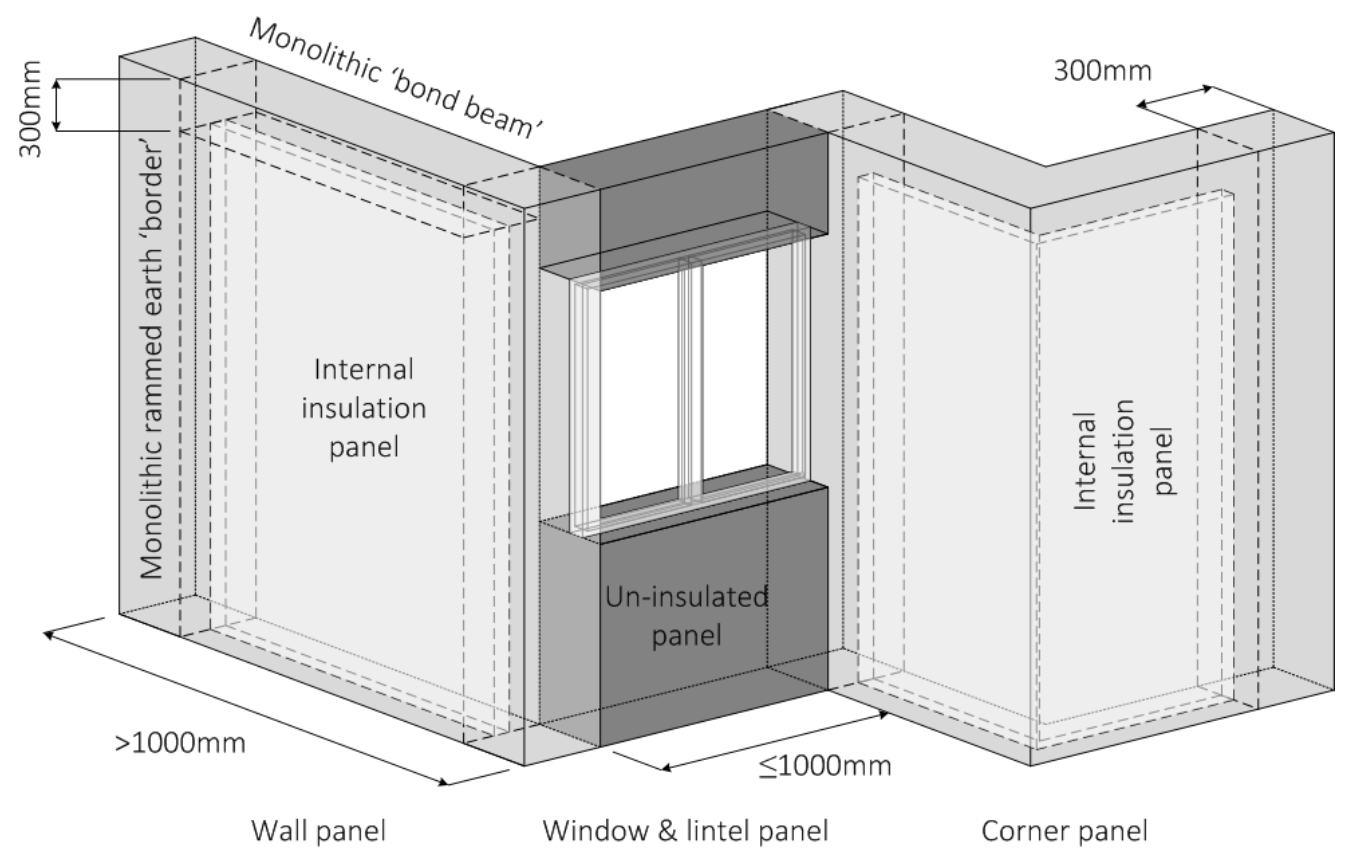

Figure 2: Insulation layout and monolithic structural components in insulated RE panels

under windows or in lintels. Resulting insulation configurations for the external walls, corner panels and lintels are shown in Figure 2.

(Insert Figure 2 somewhere near here)

\section{Instrumentation}

\subsection{Sensor Types}

The instrumentation layout was designed to accommodate changing regimes prior to and during occupancy. Prior to occupancy, temperature and humidity sensors were placed centrally at head and ceiling level in free air in the living rooms, bedrooms and kitchens to monitor indoor air temperature and humidity. Head-height sensors were then removed on occupancy to avoid damage: approaches used to determine head-level temperatures from ceiling-level data are 
discussed in the second part of this series. Sensors were also placed within the $\mathrm{RE}$ and iRE walls at head height (and additionally at knee and ceiling height in the living rooms) to monitor temperature changes with depth through the walls. A weather station sensing wind speed and direction, precipitation, dry bulb temperature and humidity was positioned between the two houses, as indicated in Figure 1. A schematic representation of the sensor deployment in this study is shown in Figure 3. Positions of all sensor groups per house are shown in Figure 4 and described in Table 1.

Multiple sensor types, obtained from three suppliers, were deployed in each of the monitored environments. Onset "HOBO" sensors were placed at room ceiling-level (A1-5), within and on the surfaces of the RE and iRE walls (H1-6) and used for the weather station. "Mannheim" sensors, provided by The University of Applied Sciences Mannheim in Germany, were used to measure indoor temperature and humidity at head-level and temperature within the RE and iRE walls. Indoor units (A1-5) comprised a single chip-mounted temperature and humidity sensor. Those placed within the walls (M1-4) comprised eight thermistors, spaced evenly along the unit's $260 \mathrm{~mm}$ length. Wall units were fitted with data cables which were connected to custom-made loggers in the attic. Finally, Digitech QP-6013 temperature and humidity sensors were paired with indoor head-level Mannheim sensors (A1-5)) to verify reliability. Digitech sensors had onboard logging and data was downloaded at the end of the unoccupied monitoring period.

(Insert Figure 3 somewhere near here)

(Insert Figure 4 somewhere near here) 


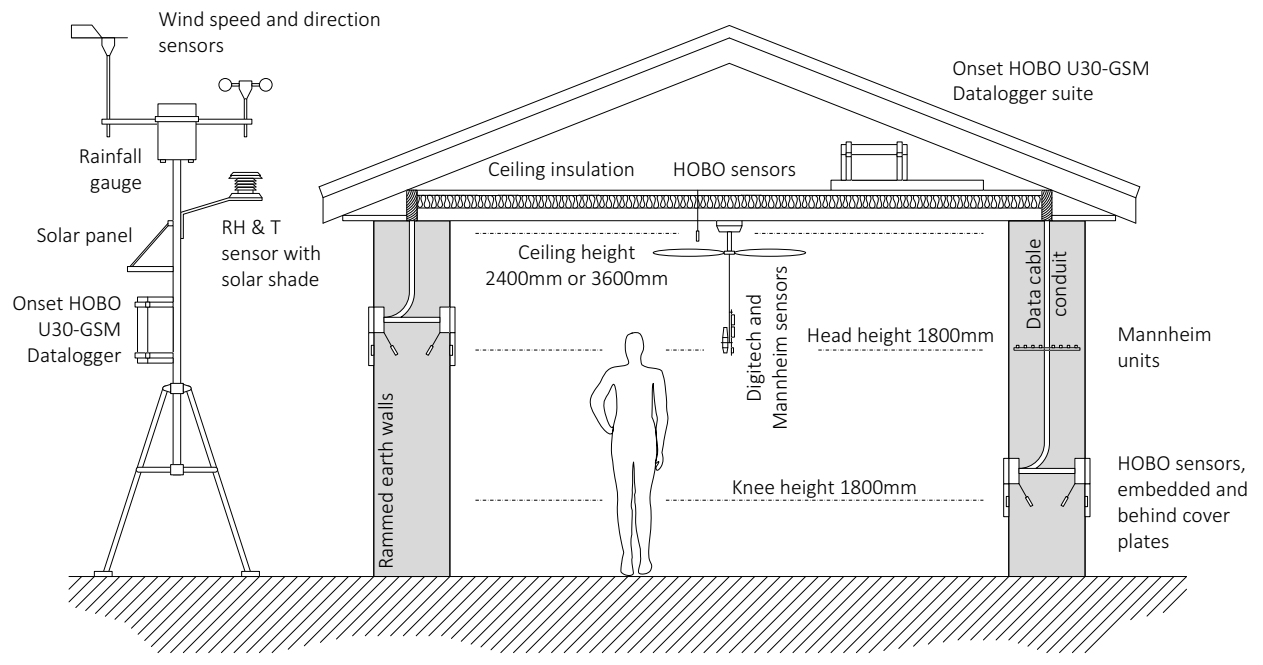

Figure 3: Diagrammatic representation of instrumentation locations. RH \& T: Relative humidity and temperature (dry bulb)

Table 1: Sensor group information for locations shown in Figure 4. T: Temperature; RH: Relative Humidity.

\begin{tabular}{lllllll}
\hline Sensor group & Height $(\mathrm{mm})$ & Position & Variables & Period (mins) & Accuracy & Type \\
\hline A1, 4 \& 5 & 1800 & Head & $\mathrm{T}, \mathrm{RH}$ & 5 & $\pm 0.4{ }^{\circ} \mathrm{C}, \pm 2 \%$ & Mannheim \\
& 1800 & Head & $\mathrm{T}, \mathrm{RH}$ & 5 & $\pm 1{ }^{\circ} \mathrm{C}, \pm 3 \%$ & Digitech \\
& 2400 & Ceiling & $\mathrm{T}$ & 10 & $\pm 0.2{ }^{\circ} \mathrm{C}$ & HOBO \\
\hline A2 & 1800 & Head & $\mathrm{T}, \mathrm{RH}$ & 5 & $\pm 0.4{ }^{\circ} \mathrm{C}, \pm 2 \%$ & Mannheim \\
& 1800 & Head & $\mathrm{T}, \mathrm{RH}$ & 5 & $\pm 1{ }^{\circ} \mathrm{C}, \pm 3 \%$ & Digitech \\
& 3600 & Ceiling & $\mathrm{T}, \mathrm{RH}$ & 10 & $\pm 0.2{ }^{\circ} \mathrm{C}, \pm 2.5 \%$ & HOBO \\
\hline A3 & 1800 & Head & $\mathrm{T}, \mathrm{RH}$ & 5 & $\pm 0.4{ }^{\circ} \mathrm{C}, \pm 2 \%$ & Mannheim \\
& 1800 & Head & $\mathrm{T}, \mathrm{RH}$ & 5 & $\pm 1{ }^{\circ} \mathrm{C}, \pm 3 \%$ & Digitech \\
& 2400 & Ceiling & $\mathrm{T}, \mathrm{RH}$ & 10 & $\pm 0.2{ }^{\circ} \mathrm{C}, \pm 2.5 \%$ & HOBO \\
\hline M1 & 3000 & Ceiling & $\mathrm{T}$ & 5 & $\pm 0.4{ }^{\circ} \mathrm{C}$ & Mannheim \\
\hline M2-4 & 1800 & Head & $\mathrm{T}$ & 5 & $\pm 0.4{ }^{\circ} \mathrm{C}$ & Mannheim \\
\hline H1, 2, 4-6 & 1800 & Head & $\mathrm{T}$ & 10 & $\pm 0.2{ }^{\circ} \mathrm{C}$ & HOBO \\
\hline H3 & 600 & Knee & $\mathrm{T}$ & 10 & $\pm 0.2{ }^{\circ} \mathrm{C}$ & HOBO \\
\hline
\end{tabular}




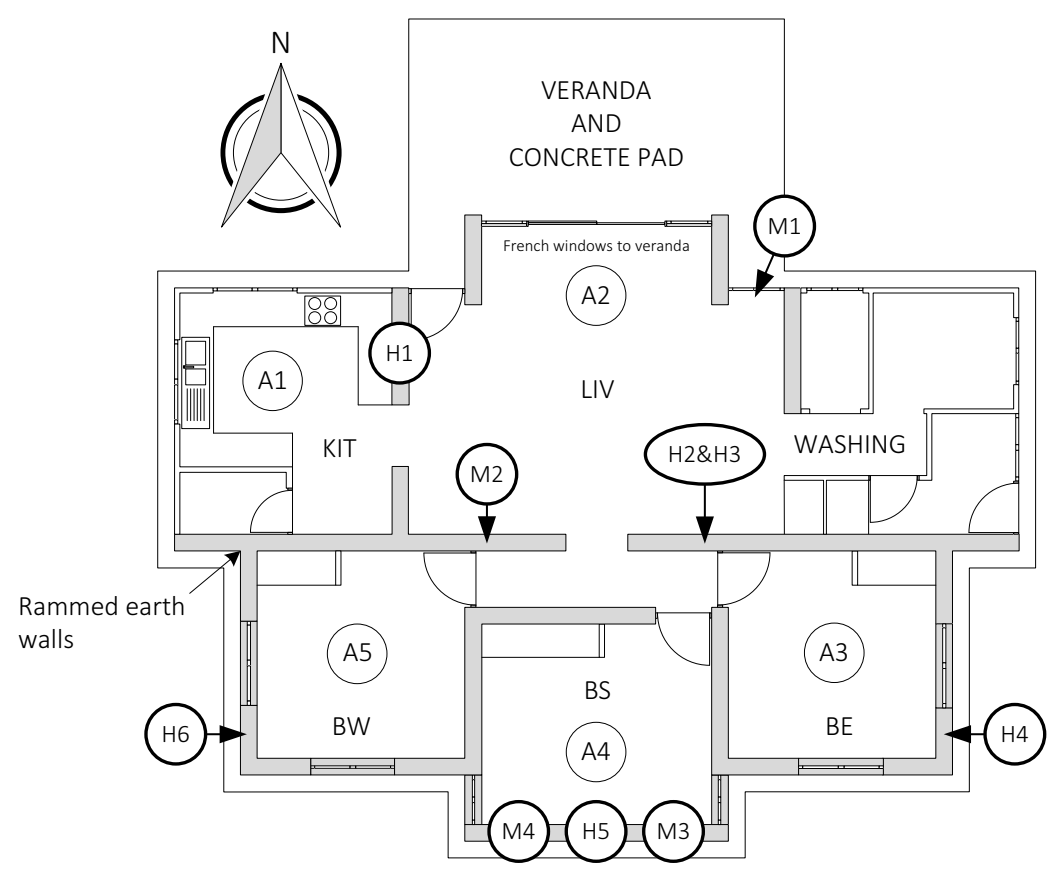

Figure 4: House plan showing sensor positions. KIT: Kitchen; LIV: Living Room; BW, BS, BE: Bedroom East, South and West respectively. Label definitions are given in Table 1. 


\subsection{Installation}

Mannheim units placed within the walls (M1-4) were installed during construction. Walls were built up to the required height and a smooth surface created upon which the unit was placed perpendicular to the wall's face, equidistant between the surfaces. The unit's central data cable was protected within a PVC conduit. Fine material was packed around the unit and cable and hand-tamped to provide good thermal contact, e.g. as shown in Figure 5. Construction then continued as per the rest of the wall, described in [4]. When in position the most extreme sensors in the units were $27.5 \mathrm{~mm}$ behind the wall's surfaces, the remainder spaced evenly at roughly $35 \mathrm{~mm}$ intervals.

HOBO wall sensors (H1-6) were installed via customised conduits. As for the Mannheim units, HOBO conduits were protected from damage by placing them on smoothed surfaces and manually packing fine material around them prior to ramming (Figure 5). Sensors were grouted into $12 \mathrm{~mm}$ diameter channels, drilled diagonally downwards from the conduit into the wall to a depth of $70 \mathrm{~mm}$ from the wall's surface. The grout comprised fine material from the parent RE material, mixed with Portland cement to provide the same thermal environment to the bulk of the wall [5]. Surface-mounted sensors were held in place and protected by insulated cover plates. Embedded and surface sensors were aligned horizontally to the desired height above the floor (configuration shown schematically in Figure 3) (Insert Figure 5 somewhere near here)

Head-level sensors within the rooms (A1-5 at 1800mm) were installed after construction was complete; paired Mannheim and Digitech sensors were suspended from the ceilings at the required height to ensure free air flow around them. Ceiling-level sensors (A1-5 at 2400 or $3600 \mathrm{~mm}$ ) were passed through existing light or fan fittings from the roof cavity to reduce their visual impact. A2 


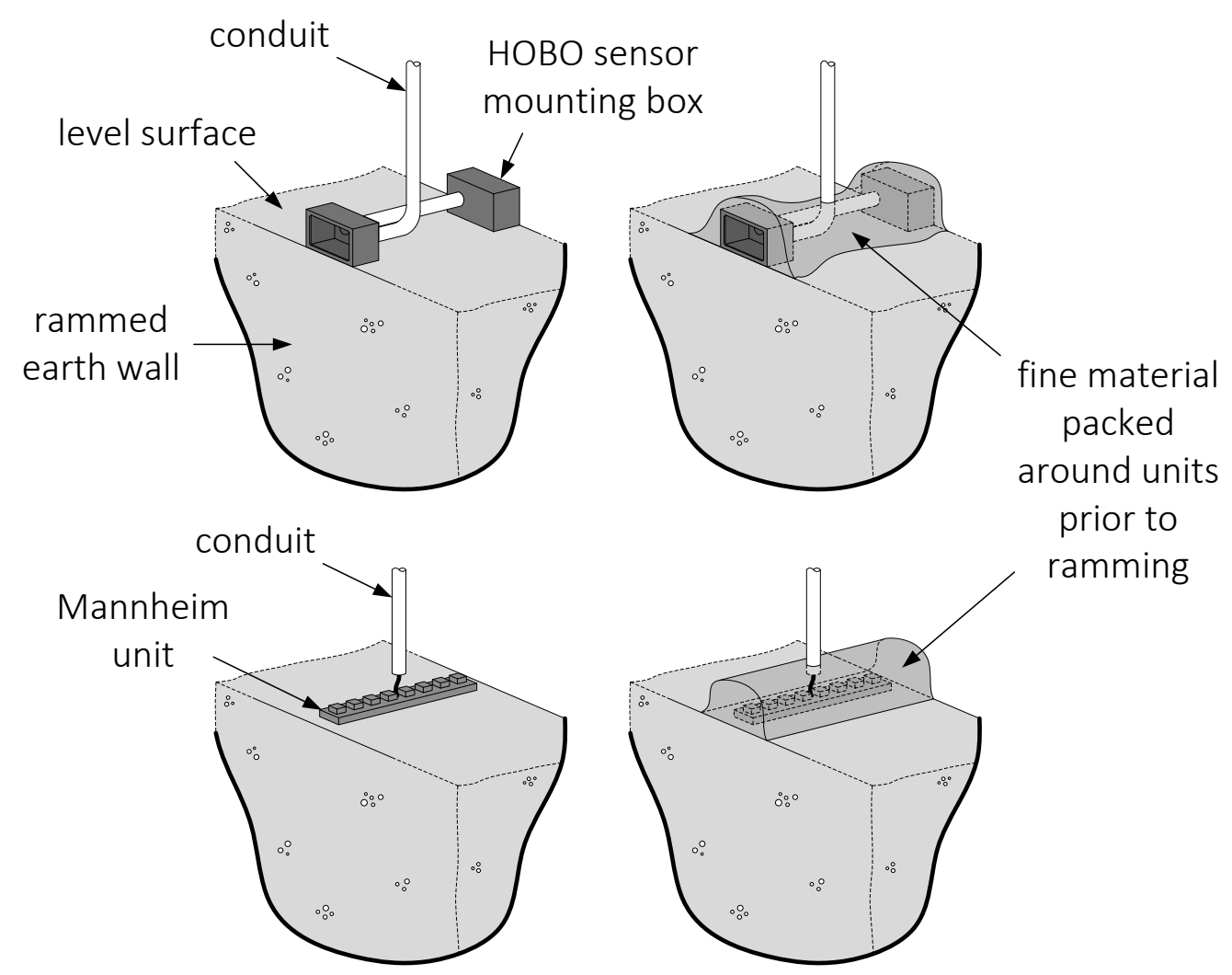

Figure 5: Packing fine material around the sensor units or conduits for protection during ramming 
was shaded from the nearby floor-to-ceiling windows by the window lintel.

\section{Measured Data}

\subsection{Collection}

The sensors generated over 16,000 measurements a day per house, continuously collected since 2014/09/01 (yyyy/mm/dd). Sensor readings were transmitted from loggers in the roof spaces of each house to cloud servers using Telstra's $2 \mathrm{G}$ and $3 \mathrm{G}$ mobile phone data networks. The following workflow was developed to manage the data. Real-time data streams were imported from third party (external weather data and the Onset HOBOLink portal) web systems. To permit remote HOBO sensor data collection, four HOBO U30-GSM loggers were used per house and a dedicated HOBO U30-GSM logger was also allocated to the weather station. Mannheim sensor data from within the walls (M1-M4) was transmitted to a cloud web server. Additionally, data from head-level Mannheim sensors (A1-5 1800mm) was transmitted wirelessly and stored locally on two customised Raspberry-pis and uploaded at the end of the unoccupied monitoring period.

\subsection{Cleaning}

Each data stream was collated, cleaned and imported into three Sqlite (www . sqlite.org) databases: outdoor (BoM and weather station data); indoor (A15); and in-wall (M1-4 and H1-6). The data analysed in this paper is from the head level sensors (A1-5), the in-wall sensors M1-M4, and public weather data from the Bureau of Meterology, recorded during the period when the house was unoccupied. The data was cleaned by removing out of range readings (e.g. $100 \mathrm{RH},+500$ temperature). Missing values up to a maximum of 2 hours were 
estimated using linear interpolation. Hourly values were generated by averaging the values from $\pm 0.5 \mathrm{hrs}$ either side of the hour in question.

\subsection{Visualisation and Analysis}

A web application was developed to provide a configurable front end for interactive visualisation of the data as time series. This interface was used for visual exploration, statistical summary analyses, data mining and for thermal modelling. Each of these applications had different requirements such as the measurement interval and temporal scope of the data, the completeness of the time series (e.g. whether missing values were allowed or not), and the number of sensor streams to be integrated. These different applications were supported as database views: that is, as virtual tables that selected and integrated the required data from the original databases in an efficient way. For additional analysis and visualisation tasks, data could be exported to $\mathrm{R}$ or MatLAB. A subset of the project data is available for viewing and download from http://datascience.ecm.uwa.edu.au:55555/.

\section{Simulated Data}

Since the early 1990s all new structures in Australia must achieve a minimum energy efficiency, expressed as a "star rating" out of 10, for construction to be permitted. A rating of 10 stars infers that the house will require almost no heating or cooling energy $\left(\leq 3 \mathrm{MJ} / \mathrm{m}^{2}\right.$.annum) to maintain a thermally-comfortable environment [9]. Star ratings are awarded based on energy efficiencies calculated by Australian Commonwealth Scientific and Industrial Research Organisation (CSIRO) accredited software. AccuRate and BERS Pro are the most popular software packages, both of which use the Chenath calculation engine. Chenath 
Table 2: Material and component thermal properties used in BERS Pro simulations

\begin{tabular}{lllll}
\hline Material/component & $\begin{array}{l}\text { Density }(\text { dry }) \\
\left(\mathrm{kg} / \mathrm{m}^{3}\right)\end{array}$ & $\begin{array}{l}\text { Resistance } \\
(\mathrm{mK} / \mathrm{W})\end{array}$ & $\begin{array}{l}\text { Capacitance } \\
\left(\mathrm{kJ} / \mathrm{m}^{3} \mathrm{~K}\right)\end{array}$ & $\begin{array}{l}\text { R-value } \\
\left(\mathrm{m}^{2} \mathrm{~K} / \mathrm{W}\right)\end{array}$ \\
\hline Rammed earth & 2000 & 0.80 & 1940.0 & - \\
Extruded polystyrene & 32 & 35.72 & 340 & - \\
Concrete & 2400 & 0.69 & 2112.0 & - \\
Steel & $\mathrm{N} / \mathrm{A}$ & 0.02 & 3900.0 & - \\
Timber (softwood) & $\mathrm{N} / \mathrm{A}$ & 10.00 & 1057.5 & - \\
\hline External surface & - & - & - & 0.04 \\
Internal surface & - & - & - & 0.12 \\
Total uninsulated wall & - & - & - & 0.40 \\
Total iRE panel & - & - & - & 2.14 \\
\hline
\end{tabular}

version 2.26 (2012) was used to assess the proposed house designs prior to construction. Both houses exceeded the minimum standard of 6/10 stars: 8.3 and 6.4 for the insulated and monolithic houses respectively (conditioned floor area $\left.99.7 \mathrm{~m}^{2}\right)$

In this study, measured performance was compared to that simulated using BERS Pro v4.3 (Chenath v3.13, released September 2015). Simulations were based on 30-year average annual temperature (as required by the rating system). Default thermal properties for relevant materials were selected to permit comparisons between previous and future analyses (Table 2). Simulations of the unoccupied houses assumed that external doors and windows remained shut and that no artificial heating or cooling (including cooking, bathing etc.) was used.

(Insert Table 2 somewhere near here)

\section{Thermal Performance Metrics}

Measured data from occupied dwellings provides 'real world' information but separating the occupants' and structures' behaviour is complex and sometimes subjective. Hence, this study split its investigation into both an unoccupied and 
an occupied phase, the latter discussed in Part B of this series, to examine the house's structural thermal performance in the absence and presence of human factors respectively. Logging of internal, unoccupied conditions was from 1st September 2014 until 1st December 2014. Doors and windows were closed during this time. Since ceiling-level sensors were disguised by light and fan fixtures, effects of light or fan activation on recorded variables were tested. However, no significant effects were found.

The following sections describes the metrics that were used to examine and compare houses' unoccupied thermal performance.

\subsection{Thermal stability}

The Thermal Stability Coefficient (TSC) expresses a structure's resistance to temperature fluctuations:

$$
\mathrm{TSC}=\frac{T_{i, \max }-T_{i, \min }}{T_{o, \max }-T_{o, \min }},
$$

where $T_{i, \max }-T_{i, \min }$ and $T_{o, \max }-T_{o, \min }$ are the range of daily indoor and outdoor dry bulb temperatures respectively [12]. The lower the TSC value, the better the structure or room was as mitigating outdoor temperature extremes.

\subsection{Thermal lag}

Thermal lag is the time difference between daily peak outdoor and indoor temperatures. RE structures are traditionally considered to boast long thermal lags: it is this property that is commonly (and incorrectly) associated with good 'insulative' properties. Rather, RE has poor thermal resistance but a high thermal mass [22]. Thermal lag is a popular parameter to describe the performance of high thermal mass structures (e.g. Hall and Allinson [14]) and so permits a 
comparison between this and other assessments. However, evaluating thermal lag in real-world conditions can be troublesome, in that lags must be calculated for periods displaying nominally-sinusoidal temperature fluctuations which are not always the case in practice. Filters were applied to measured and simulated data to select appropriate days for calculating thermal lag, as illustrated in Figure 6 . Appropriate days had to satisfy the following properties:

1. The time of the daily minimum must precede that of the maximum for both inside and outside measurements, e.g. the first 24 hour period shown in Figure 6. Days that do not meet this sinusoidal constraint are unsafe and so excluded. Typically in Kalgoorlie-Boulder the outdoor minima occurs around 06:00 and the outdoor maxima around 16:00.

2. Negative 'lags' can occur due to sudden drops in outdoor temperature (e.g. the second and third 24 hour period in Figure 6). Such unsafe days were excluded.

3. For unsafe days of type 1 or 2 (above) the following two days were also excluded to avoid anomalies from extreme weather events.

4. Any days where the time of the indoor peak was too uncertain were excluded (final 24 hours in Figure 6). One source of uncertainty was days with multiple peaks where more than three hours were within $0.01^{\circ} \mathrm{C}$ of the maximum value. Another source of uncertainty was when the indoor maxima occurred across a day boundary (between 22:00 and 01:00). For days with 3 or fewer hours within $0.01^{\circ} \mathrm{C}$ of the maximum value, the final such hour was taken as the peak, so reporting the upper bound for the thermal lag. Finally, thermal lags of 0 hours were allowed.

(Insert Figure 6 somewhere near here) 


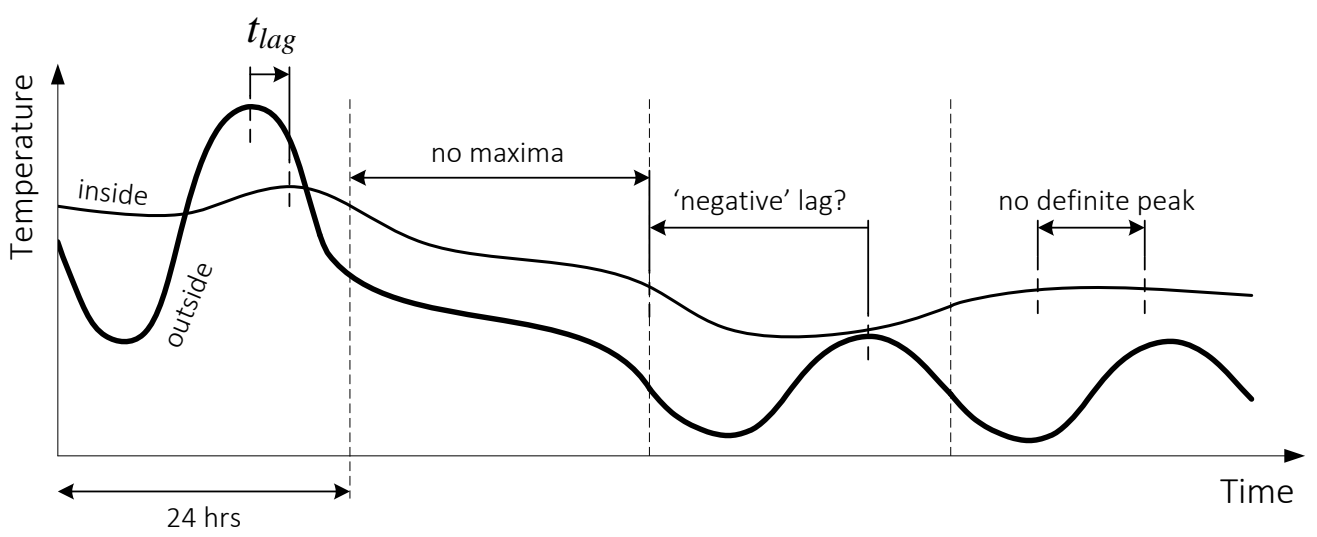

Figure 6: Filtering processes used to define thermal lag

\section{Results and Discussion}

The following questions were addressed:

1. To what extent did the houses mitigate outdoor temperature extremes?

2. To what extent did indoor temperature peaks lag outdoor peaks?

3. To what extent did the performance of the monolithic and insulated houses differ?

4. To what extent did the measured and predicted behaviours differ?

Two sets of climate data were used for the analysis. BERS Pro simulations were based on 30-year average annual temperature data (as required by the rating system). The measured climate data was from the nearest Bureau of Meteorology weather station at Kalgoorlie airport. The two datasets were statistically different (unpaired Welch Two sample t-test $p$ value $=8.996 e-27$ ): simulated climate data was colder than measured values by roughly $2^{\circ} \mathrm{C}$ but shared a similar interquartile range. As diurnal temperature ranges were similar, however, direct comparisons between measured and simulated thermal stability and thermal lag were valid. 

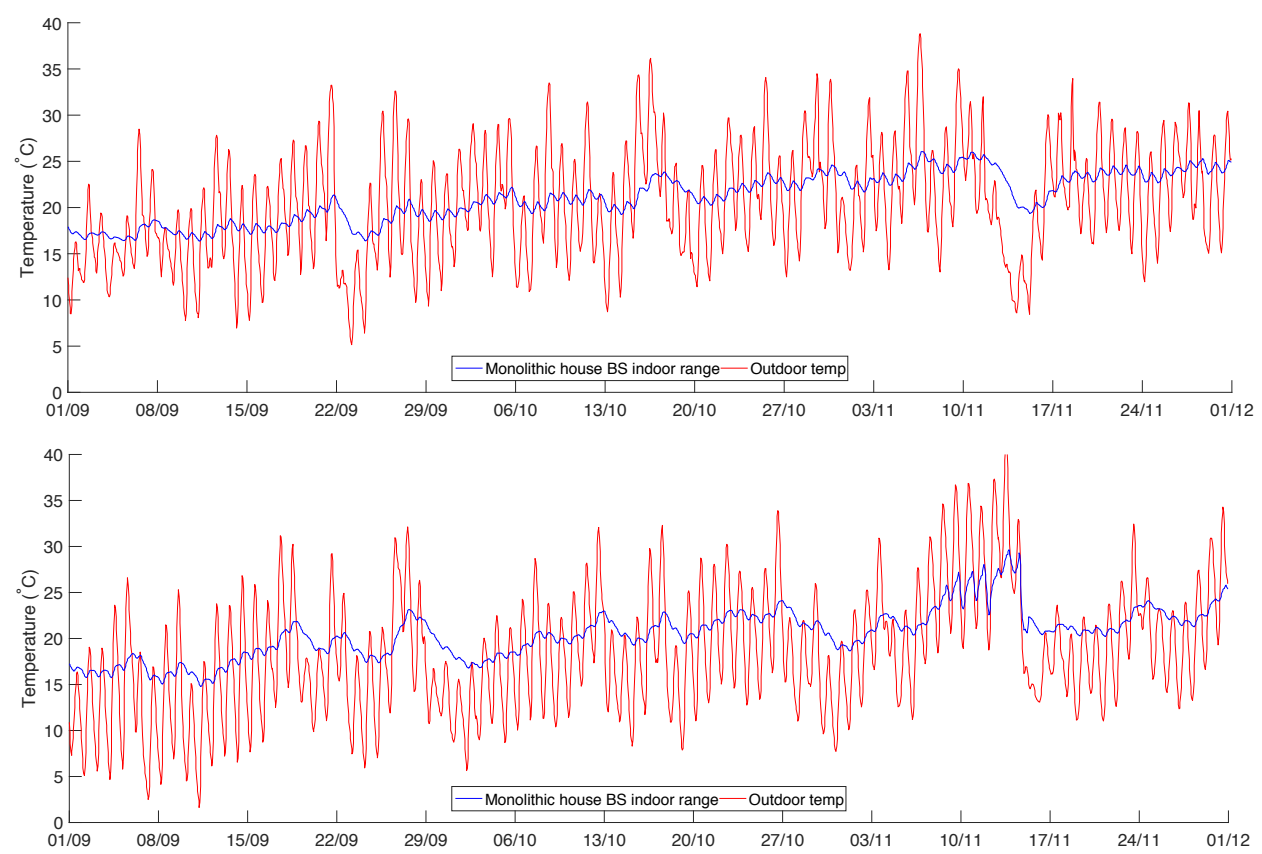

Figure 7: Monolithic house southern bedroom (BS) indoor and outdoor dry bulb temperatures for measured (top) and simulated (bottom) data. Outdoor temperatures are 2014 measurements or 30 year average for the simulations.

\subsection{Thermal stability}

An example of indoor and outdoor dry bulb temperature data captured in the southern bedroom (the room with the greatest RE or iRE envelope) is shown in Figure 7 (top). BERS Pro simulated data for the same period is shown in Figure 7 (bottom). Results in the insulated house were visually identical and so are not shown.

(Insert Figure 7 somewhere near here)

\subsubsection{Measured performance}

TSC results for the iRE and RE houses, using both measured and simulated data, are given in Table 3. TSCs in all rooms in both houses were between the ranges found by Serrano et al. [21] for insulated and uninsulated test cells $(0.030-$ 
0.256 respectively). TSC variation from day to day was minimal: the few spikes that occurred corresponded to rapid changes in cloud cover.

Stability differences between houses were small but not statistically significant (unpaired $p$ value 0.0559): over this analysis period both houses mitigated temperatures equally well. However, given that $p$ was close to 0.05 , a longer period or a period comprising different seasons may have demonstrated significant differences. Kitchen and then living room TSCs were the highest for both houses, i.e. these rooms mitigated temperature extremes the most poorly. Mean living room and kitchen TSCs were lower (i.e. better) in the insulated house; poorer performance in the monolithic house may indicate reduced external shading, perhaps due to its higher elevation or exposed eastern rooms (e.g. no shading from the central carport). Bedroom TSCs were similar for both houses and the southern bedrooms produced the lowest TSCs. This variation between rooms agreed well with the distribution of internal and external thermal mass; rooms with greater RE or iRE envelopes produced lower TSCs. Notably, whether the envelope comprised RE or iRE made no statistical impact.

\subsubsection{Simulated performance}

All simulated TSCs were higher (i.e. worse) than measured values for corresponding rooms (all unpaired $p<0.0000$ ). However, simulated TSCs between the houses were statistically similar (unpaired $p=0.2171$ ): neither house was predicted to outperform the other. The quality of the simulated performances' match to measured values varied with the room envelopes' thermal masses: the southern bedrooms gave the lowest TSCs and showed the best match to measured performance, whereas kitchen and living room TSCs were the highest and almost double those measured. Therefore, for the houses investigated here, the default 
Table 3: TSCs per monitored room for both houses. Bold entries indicate maximum values. TSC: Thermal Stability Coefficient; SD: Standard Deviation; $n$ sample size

\begin{tabular}{llllllll}
\hline House & \multirow{2}{*}{ Room } & \multicolumn{2}{c}{ Measured } & \multicolumn{4}{c}{ Simulated } \\
& & TSC & SD & N & TSC & SD & N \\
\hline Insulated & Liv & 0.143 & 0.078 & 61 & $\mathbf{0 . 4 2 7}$ & $\mathbf{0 . 0 6 9}$ & 91 \\
& BE & 0.117 & 0.069 & 91 & 0.171 & 0.082 & 91 \\
& BS & 0.108 & 0.089 & 91 & 0.145 & 0.077 & 91 \\
& BW & 0.143 & 0.100 & 91 & 0.193 & 0.076 & 91 \\
& Kit & $\mathbf{0 . 1 4 7}$ & $\mathbf{0 . 0 8 9}$ & 91 & 0.419 & 0.072 & 91 \\
\hline Monolithic & Liv & 0.185 & 0.109 & 61 & $\mathbf{0 . 4 2 5}$ & $\mathbf{0 . 0 6 9}$ & 91 \\
& BE & 0.106 & 0.060 & 91 & 0.146 & 0.087 & 91 \\
& BS & 0.103 & 0.089 & 91 & 0.119 & 0.084 & 91 \\
& BW & 0.146 & 0.100 & 91 & 0.160 & 0.078 & 91 \\
& Kit & $\mathbf{0 . 1 9 1}$ & $\mathbf{0 . 0 9 6}$ & 91 & 0.414 & 0.070 & 91 \\
\hline
\end{tabular}

BERS Pro stability predictions were overly pessimistic.

(Insert Table 3 somewhere near here)

\subsection{Thermal lag}

Thermal lags found per room are given in Table 4. Comparing the overall performance of each house, measured values showed that both houses performed significantly similarly (unpaired $p=0.3898$ ): both houses were just as capable at offsetting peak indoor temperatures. However, simulated thermal lags were significantly different between houses (unpaired $p=0.01124$ ): the monolithic house outperformed the insulated house (longer thermal lags).

(Insert Table 4 somewhere near here)

\subsubsection{Measured performance}

Contrasting the individual rooms between houses demonstrated small but significant differences in all but the western bedrooms ( $p$ values Liv $=0.0425$, $\mathrm{BE}=0.0002, \mathrm{BS}=0.0000, \mathbf{B W}=\mathbf{0 . 0 9 3 8}, \mathrm{Kit}=0.0031)$ : within the confidence of the data, lags were shorter in the insulated house, i.e. converting walls to iRE 
Table 4: Thermal lags per monitored room. TL: Mean thermal lag; SD: Standard Deviation; $\mathrm{N}$ : sample size (days with "safe" measurements). "Simulated BS had many unsafe days with maxima across the day boundary.

\begin{tabular}{llllllll}
\hline House & Room & \multicolumn{3}{l}{ Measured (hrs) } & \multicolumn{3}{l}{ Simulated (hrs) } \\
& & TL & SD & N & TL & SD & N \\
\hline Insulated & Liv & 0.480 & 0.770 & 25 & 0.690 & 1.538 & 29 \\
& BE & 0.650 & 0.893 & 40 & 2.085 & 1.195 & 47 \\
& BS & 0.805 & 0.928 & 41 & 2.444 & 1.486 & 45 \\
& BW & $\mathbf{0 . 9 4 9}$ & $\mathbf{1 . 1 4 6}$ & 39 & 3.080 & 0.900 & 50 \\
& Kit & 0.850 & 1.210 & 40 & $\mathbf{3 . 4 6 0}$ & $\mathbf{1 . 6 3 1}$ & 50 \\
\hline Monolithic & Liv & 0.364 & 0.658 & 22 & 0.357 & 1.193 & 28 \\
& BE & 0.864 & 0.930 & 44 & 2.818 & 1.263 & 44 \\
& BS & $\mathbf{1 . 5 0 0}$ & $\mathbf{1 . 1 5 1}$ & $\mathbf{4 4}$ & $\mathbf{5 . 7 5 0}$ & $\mathbf{1 . 9 6 0}$ & $\mathbf{1 2}^{*}$ \\
& BW & 0.658 & 0.966 & 38 & 3.523 & 1.089 & 44 \\
& Kit & 0.583 & 0.806 & 36 & 3.400 & 1.629 & 50 \\
\hline
\end{tabular}

marginally reduced the room's ability to offset peak temperatures. In all cases, thermal lag increased with greater thermal mass envelope, as anticipated. Rooms with longer thermal lags also demonstrated lower TSCs.

Measured mean lags were $<1$ hour in most cases: the lower bound of those previously reported for RE structures comprising similar wall thicknesses and densities. For example, Daniel et al. [11] measured lags of 1-2 hours in South Australia (Köppen climate classifications Cfb and Csa) and Milani and Labaki [18] around 4 hours in southeast Brazil (Cfa). Longer lags were found by Soebarto [22] (6 hours in South Australia ,Csb) and Baggs et al. [2] and Serrano et al. [21] reported lags of up to 10 hours in Summer (Csa). In general, longer lags were found for single-room structures with good control over internal conditions (e.g. unoccupied "test cells" with few or no windows or doors). Shorter lags were associated with occupied, multi-room dwellings. Results found here suggest that thermal lags for real RE houses fall towards the lower end of this spectrum, i.e. the common claim that RE structures boast high thermal lags is perhaps an 
exaggeration.

\subsubsection{Simulated performance}

Simulated thermal lags were longer than measured values in both houses; excepting the living rooms, lags were $\geq 2$ hours. Lags differed significantly between the houses in the bedrooms but not in the living rooms or kitchens ( $p$ values $\mathbf{L i v}=\mathbf{0 . 1 0 5 8}, \mathrm{BE}=0.0000, \mathrm{BS}=0.0106, \mathrm{BW}=0.0035, \mathbf{K i t}=\mathbf{0 . 6 5 9 3})$. Overall, the monolithic house achieved the longest thermal lags. However, it should be noted that a high number of "unsafe" days were simulated in the monolithic house's southern bedroom, reducing the sample size: its high $>5$ hour lag is not reliable.

The match between simulated and measured thermal lags was poor in all rooms but the living rooms: lags were up to triple their measured counterparts. Matches were poorest in those rooms with more massive envelopes. Notably, these rooms all displayed several examples of days with two peak temperatures, the second often higher than the first, separated by up to two hours. These 'secondary' peaks were associated with incident solar radiation and so worsened from East to West. Hence, simulated lags in the kitchen were also poorly matched to measured values, despite that room's less massive envelope: as the westernmost room, incident sunlight affected that room last. These effects were not found in reality and it is unclear why they arose in the simulations, given the high solar elevation (approaching Summer) and the houses' large eaves. However, it was evident that such peaks greatly skewed anticipated thermal lag values.

\subsection{Temperature profiles in the walls}

The southernmost wall (running East-West) in the southern bedrooms, as the longest expanse of continuous RE or iRE in either house, was instrumented (M3, M4 and H5) to monitor temperature profiles through it and relate those 
to temperature fluctuations within and outside the room. Temperature profiles through the walls over five consecutive days (each with nominally-sinusoidal outdoor temperature variation) are shown in Figure 8. Results for M3 \& M4 are the average of the two groups. The inset plots in Figure 8 show:

- the average change in recorded temperature amplitude per sensor in the unit (M3 and M4), termed the "temperature amplitude ratio", TAR (TAR = $\ln \frac{\Delta T_{i}}{\Delta T_{i+1}}$ where $\Delta T_{i}$ and $\Delta T_{i+1}$ are the diurnal temperature ranges measured at sensors $i$ and $i+1)$;

- the time delay between recorded peak temperatures.

In both cases, shaded regions show one standard deviation about the mean (solid line). As each Mannheim unit comprised eight individual sensors, the TAR and time delays were calculated over seven intervals (number 1 being between the pair closest to the wall's inside face).

(Insert Figure 8 somewhere near here)

In both houses, it is obvious from Figure 8 that indoor temperature led that in the walls, i.e. peak indoor temperatures occurred before those recorded by those sensors nearest to the wall's inside face. The same result was found for the surface-mounted sensors (H5). In the monolithic RE wall, TAR and delay reduced from the wall's outer to the inner face. Such a result was not expected: rather, if heat exchange was purely driven by outdoor temperature, the reducing thermal gradient between sensor pairs would be expected to produce constant TAR and increasing delays [7]. Hence, heat transfer through the walls responded to, rather than controlled, indoor air temperature. Instead, indoor air temperature was seemingly largely governed by factors more in-phase with the outdoor air, for example solar radiation through windows, outdoor air ingress or heating 

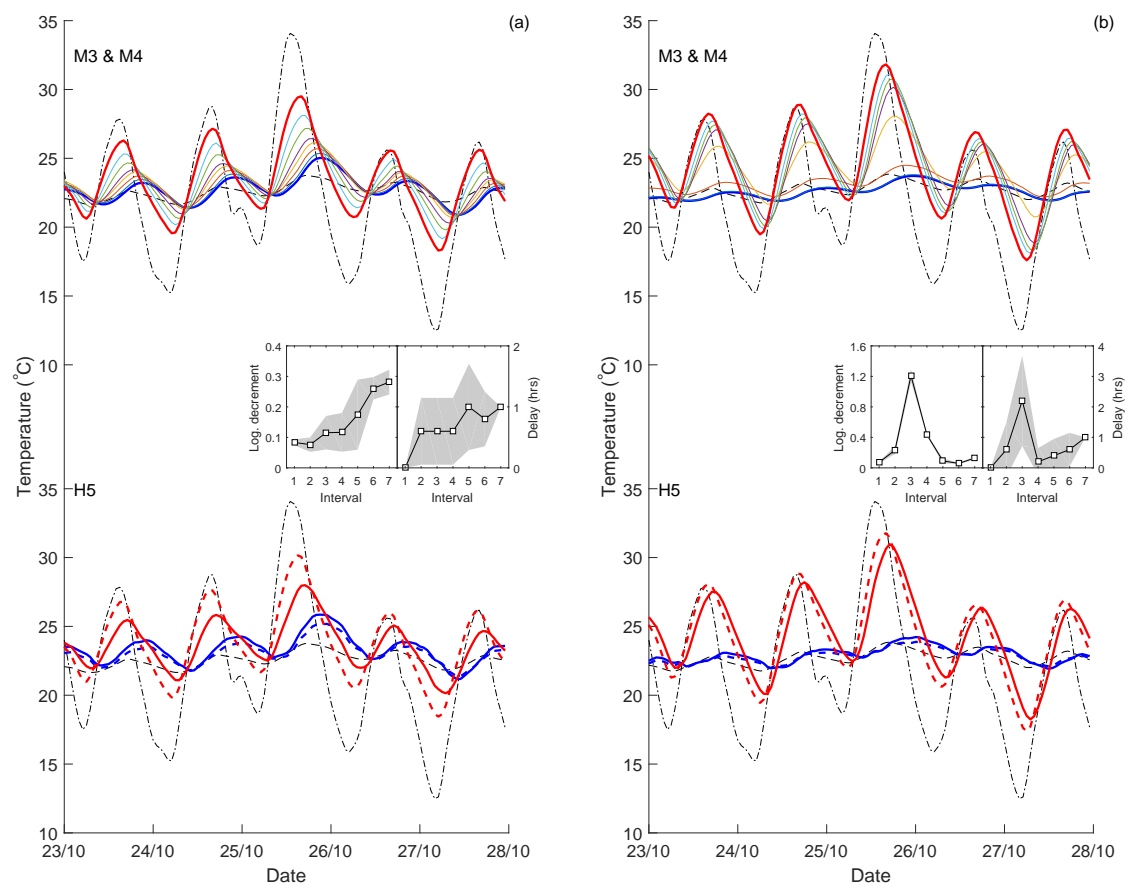

Figure 8: Southern bedroom wall temperature profiles: a) monolithic house; b) insulated house. Sensor groups numbered as per Figure 4. Black dash-dotted line (-.): Outdoor temperature. Black dashed line (- -): Indoor temperature. Bold red and bold blue lines: innermost and outermost sensors respectively. Dashed bold red and blue lines: outdoor and indoor wall surface temperatures respectively. Inset: mean logarithmic temperature decrement and delay between Mannheim sensor intervals. 
effects from the ceiling. In the iRE wall, TAR increased significantly across the insulation as did delay. Increased TAR demonstrated that the insulation resisted heat transfer between the two RE leaves, as expected. However, no delay would be expected across the insulation, as delay indicates thermal communication. The commensurate increase in delay indicates that the wall continued to exhibit massive element behaviour, i.e. the two RE leaves remained thermally connected. Cold bridging between the leaves may have arisen due to the vertical data cable conduit, which intersected the insulation. Consequently, temperature profiles within the iRE walls also lagged indoor temperature by roughly four hours.

These results support TSC and thermal lag results discussed above when compared to previous works. For those structures with few windows or doors, thermal lag and stability is strongly controlled by heat transfer through the walls, giving rise to high thermal lags. However, in more complex structures, heat transfer is governed by additional mechanisms, somewhat bypassing the walls and negating their benefits.

\subsection{Consequences of incorporating iRE}

A key aim of this study was to identify any thermal benefits associated with the more complex and costly iRE construction. For the specific circumstances investigated in this work, results showed that the inclusion of iRE had no statistical impact on house thermal performance. Despite prediction quality issues, BERS Pro simulations also indicated that the inclusion of iRE would make no significant benefit. 


\section{Conclusions}

This paper examined the structural thermal performance of two rammed earth houses in Kalgoorlie-Boulder, Western Australia. The houses were built to optimise passive solar performance and comprised mixes of RE, iRE and lightweight insulated walls. A substantial sensor and logging array was installed and performance was also simulated using the state-of-the-art thermal modelling software BERS Pro v4.3, as an example of that used for energy efficiency accreditation in Australia.

Measured data showed that both houses performed similarly when unoccupied in terms of both thermal stability and thermal lag. Measured thermal stabilities were similar to those found in previous studies. However, thermal lags were shorter. Temperature profiles through the walls demonstrated that low thermal lags were due to indoor air temperatures responding to additional factors, i.e. that the massive walls were not the sole contributor to indoor performance.

Thermal stabilities calculated from simulated data were similar for both houses. However, simulations predicted longer thermal lags in the monolithic house (i.e. that only comprising solid cement-stabilised rammed earth walls). Results showed that this was due to unrealistic indoor air temperature spikes occurring in the early evenings, associated with incident sunlight. The overall match between simulated and measured performance was poor: measured performance was superior for both houses.

Overall, results showed that including iRE in the houses' external envelopes afforded no advantage to thermal performance. However, it is emphasized that this result is only for those specific circumstances investigated here and that insulation may afford benefits in other climates or when a house is occupied. 


\section{Acknowledgements}

451 The authors would like to thank Mr Adrian Welke of Troppo Architects 452 for his input throughout the project. We would also like to thank Mr Barron 453 Bonney of the Indigo Mining Services for his help with running initial exper454 iments and on-site technical support. Funding for this project was from the 455 Australian Research Council (ARC), the Western Australia Department of Hous456 ing Go8-DAAD. Work presented here was conducted under ARC Linkage Grant 457 LP140100375 and UWiN - Underground Wireless Sensor Networks. This research 458 was approved by the Human Research Ethics Office of the University of Western 459 Australia (RA/4/1/7273). 


\section{References}

[1] Allinson, D., Hall, M., 2010. Hygrothermal analysis of a stabilised rammed earth test building in the UK. Energy and Buildings 42, 845-852.

[2] Baggs, S. A., Baggs, J. C., Baggs, D. W., 1991. Australian earth-covered building. Kensington, New South Wales University Press, Australia.

[3] Ball, A., Ahmad, S., Bernie, K., McCluskey, C., Pham, P., Tisdell, C., Willcock, T., Feng, A., 2015. Australian energy update 2015.

URL http://www.industry.gov.au/Office-of-the-Chief-Economist/Publications/ Documents/aes/2015-australian-energy-statistics.pdf

[4] Beckett, C. T. S., Ciancio, D., 2014. Effect of compaction water content on the strength of cement-stabilised rammed earth materials. Canadian Geotechnical Journal 51 (5), 583-590.

[5] Beckett, C. T. S., Ciancio, D., September 1-3 2014. Effect of microstructure on heat transfer through compacted cement-stabilised soils. In: Geomechanics from Micro to Macro. Vol. 2 of ISSMGE International Symposium on Geomechanics from Macro to Micro. University of Cambridge, CRC Press, Cambridge, UK, pp. 1539-1544.

[6] Cardell-Oliver, R., 2013. Water use signature patterns for analyzing household consumption using medium resolution meter data. Water Resources Research 49 (12).

[7] Carslaw, H. S., Jaeger, J. C., 1959. Conduction of heat in solids. Oxford University Press, London (UK).

[8] Ciancio, D., Jaquin, P., Walker, P., 2013. Advances on the assessment of soil suitability for rammed earth. Construction and Building Materials 42, 40-47.

[9] Daniel, L., Soebarto, V., Williamson, T., 2012. Evaluating the suitability of the AccuRate engine for simulation of massive construction elements. In: Proceedings of the 46th Annual Conference of the Architectural Science Association (ANZAScA). Griffith University, Queensland (Australia).

[10] Daniel, L., Soebarto, V., Williamson, T., 25-28 August 2013. Assessing the simulation capability of the AccuRate engine in modelling massive construction elements. In: Proceedings of the 13th International Conference of the International Building Performance Simulation Association. International Building Performance Simulation Association, Chambery, France.

[11] Daniel, L., Soebarto, V., Williamson, T., 2015. House energy rating schemes and low energy 
dwellings: The impact of occupant behaviours in australia. Energy and Buildings.

[12] de Gracia, A., Castell, A., Medrano, M., Cabeza, L. F., 2011. Dynamic thermal performance of alveolar brick construction system. Energy Conversion and Management 52, 2495-2500.

[13] Dong, X., Soebarto, V., Griffith, M., 2015. Design optimization of insulated cavity rammed earth walls for houses in australia. Energy and Buildings 86, 852-863.

[14] Hall, M., Allinson, D., 2008. Assessing the moisture-content-dependent parameters of stabilised earth materials using the cyclic-response admittance method. Energy and Buildings 40 (11), 2044-2051.

[15] Jaquin, P. A., Augarde, C. E., Gerrard, C. M., 2008. A chronological description of the spatial development of rammed earth techniques. International Journal of Architectural Heritage: Conservation, Analysis and Restoration 2 (4), 377-400.

[16] Krayenhoff, M., 10-13 February 2015. Rammed earth in a concrete world. In: Rammed earth construction. First International Conference on Rammed Earth Construction. University of Western Australia, Perth, WA, pp. 111-114.

[17] Marker, T., McLeod, P., Harrington, P., 2012. Increased housing energy efficiency standards in WA: Benefit cost analysis.

URL https://www.commerce.wa.gov.au/sites/default/files/atoms/files/ energyefficiencycostbenefit.pdf

[18] Milani, A. P. d. S., Labaki, L. C., 2012. Physical, mechanical, and thermal performance of cement-stabilized rammed earthrice husk ash walls. Journal of Materials In Civil Engineering $24(6), 775-782$.

[19] OECD, 2003. Environmentally sustainable buildings: Challenges and policies. Tech. rep., Organisation for Economic Co-operation and Development.

[20] Page, A., Moghtaderi, B., Alterman, D., Hands, S., 2011. A study of the thermal performance of Australian housing. Priority Research Centre for Energy, The University of Newcastle.

[21] Serrano, S., de Gracia, A., Cabeza, L. F., 2016. Adaptation of rammed earth to modern construction systems: Comparative study of thermal behavior under summer conditions. Applied Energy 175, 180-188.

[22] Soebarto, V., July 2009. Analysis of indoor performance of houses using rammed earth walls. In: Eleventh International IBPSA Conference. Glasgow, Scotland, pp. 1530-1537. 
[23] Taylor, R. A., Phelan, P. E., Otanicar, T., Prasher, R. S., Phelan, B. E., 2012. Socioeconomic impacts of heat transfer research. International Communications in Heat and Mass Transfer 39, 1467-1473.

[24] van Straaten, J. F., 1967. Thermal performance of buildings. Elsevier Publishing Company, Amsterdam. 